\title{
EchoGéo
}

$19 \mid 2012$

Du littoral à la haute mer : quelles recherches récentes en géographie?

\section{L'algoculture et ses contraintes géographiques en Chine}

\section{Sophie Litzler}

\section{OpenEdition}

\section{Journals}

Édition électronique

URL : https://journals.openedition.org/echogeo/12913

DOI : 10.4000/echogeo.12913

ISSN : 1963-1197

Éditeur

Pôle de recherche pour l'organisation et la diffusion de l'information géographique (CNRS UMR 8586)

Référence électronique

Sophie Litzler, «L'algoculture et ses contraintes géographiques en Chine », EchoGéo [En ligne], 19| 2012, mis en ligne le 10 février 2012, consulté le 10 août 2021. URL : http://journals.openedition.org/ echogeo/12913; DOI : https://doi.org/10.4000/echogeo.12913

Ce document a été généré automatiquement le 10 août 2021.

EchoGéo est mis à disposition selon les termes de la licence Creative Commons Attribution - Pas d'Utilisation Commerciale - Pas de Modification 4.0 International (CC BY-NC-ND) 


\title{
L'algoculture et ses contraintes géographiques en Chine
}

\author{
Sophie Litzler
}

1 Les étendues à perte de vue des cultures marines sur le littoral de la Chine du nord offrent la sensation rare que les hommes peuvent enfin cultiver la mer. Elles nourrissent des hommes mais surtout leurs espoirs de nouvelle conquête agricole. Nous apportons ici une analyse géographique nécessaire de ces vastes cultures, de leurs contraintes et de leurs productions qui dans la nouvelle modernité chinoise sont en réalité sujettes d'autant d'espoir que d'inquiétude.

2 Les algues ne se réduisent pas aux phénomènes de marées vertes qui touchent les estrans de Bretagne (Gournay ; Le Délézir, 2011) ou de Chine. Présenter une thématique de recherche sur les algues, c'est tenter d'aller au-delà de la vision médiatique ou de l'opinion publique qui les perçoit en général de façon négative. Si nous changeons d'échelle et que nous portons un regard scientifique vers le monde asiatique, nous nous apercevons que l'algue est un végétal marin d'une grande valeur industrielle et commerciale cultivé intensivement depuis les années 1970 (les algues brunes cultivées s'échangent à 2000 euros la tonne sur le marché mondial) ${ }^{1}$. Les enjeux de cette culture sont aussi économiques, en permettant une main-d'œuvre nombreuse et en constituant une filière agro-alimentaire performante sur un des rares espaces de conquête agricole : l'estran et la zone marine littorale ; les enjeux sont écologiques : la culture des algues avec la culture des coquillages et des poissons participent par exemple positivement au bilan carbone chinois avec une capture officielle de 1,4 million de tonnes de $\mathrm{CO}_{2}$ en 2006 (Fang, 2009).

3 La culture des algues marines s'est développée en lien avec une industrialisation rurale endogène polarisée par le développement littoral du golfe de Bohai et son intégration au marché urbain des pôles dynamiques de Dalian, Tianjin et Pékin. L'étude de cette culture permet de présenter des particularités locales dans les mutations économiques du monde rural et la transformation des campagnes littorales analysée par Thierry Sanjuan (essentiellement pour les campagnes littorales méridionales du delta de la rivière des Perles) (Sanjuan, 1997). Dans les provinces littorales du Nord à l'image des 
campagnes du Sud dans les années 1980 et sous l'impulsion de bourgs dynamiques ou d'entreprises collectives, agriculteurs et pêcheurs se tournent vers des cultures plus rentables. Ici celle des algues ne concurrence toutefois pas l'espace agricole des rizières, des étangs à poissons ou de l'expansion urbaine. C'est une culture peuplante et fortement intégrée à un circuit agro-alimentaire national et à des réseaux commerciaux. Cette culture des algues nous donne un exemple de la pluralité des développements littoraux ouverts de plus en plus sur le monde comme le synthétisent Thierry Sanjuan et Pierre Trolliet (Sanjuan, 2007 ; Sanjuan, Trolliet, 2010)2 .

4 La culture massive des algues respecte des contraintes techniques qui en déterminent sa géographie mais subit pourtant aujourd'hui de nouvelles difficultés : la concurrence territoriale et les conflits d'usage sur un espace littoral en plein développement, des pollutions multiformes issues de l'intensification de leur culture, des pollutions fluviales, comme les risques industriels (récemment des deux grandes marées noires chinoises du golfe de Bohai à Dalian en juillet 2010 et depuis le 3 juin 2011 -plate-forme pétrolière Penglai 19-3- qui ont atteint la production agro-marine de zones exceptionnelles de culture intensive de la Chine littorale) ${ }^{3}$.

5 Ce domaine de recherche peut être abordé d'un point de vue biologique et phycologique eu égard à la multitude d'espèces d'algues. Les algues rassemblent trois familles: les brunes, les rouges et les vertes. Au sein de ces familles, on dénombre plusieurs milliers d'espèces dont toutes les propriétés sont encore à identifier par les sciences phycologiques ${ }^{4}$. À ces trois familles il faut rajouter une autre catégorie: ces macro-algues brunes, vertes ou rouges diffèrent elles-mêmes des micro-algues et leurs valorisations n'ont rien en commun. Notre article porte exclusivement sur les macroalgues, cultivées à des fins alimentaires ou industrielles. De par leur valorisation énergétique, les micro-algues sont une culture en devenir et un enjeu de plus en plus important, essentiellement pour d'autres domaines: la santé et la transition énergétique.

6 L'espace étudié des macro-algues se trouve en Chine, premier producteur mondial avec 10 millions de tonnes cultivées pour l'année $2008^{5}$. Les autorités chinoises ont revu toutefois à la baisse leur production aquacole, qui inclut les algues, en signalant à la FAO un recul de $13 \%$ de leur production en $2010^{6}$. Cette tendance récente peut être illustrée par des exemples locaux de disparition des espaces de culture. Face à la croissance économique des littoraux chinois, la culture des algues est ainsi fragilisée.

7 À partir de ce constat, nous nous sommes interrogés sur les causes du recul de la production chinoise et plus généralement sur les contraintes géographiques qui peuvent limiter ou menacer l'algoculture chinoise.

8 Nous présenterons ainsi un état des lieux de la production des algues dans le monde et en Chine en soulignant les valorisations économiques de cette culture. Nous établirons alors une typologie des contraintes naturelles, environnementales et anthropiques qui réduisent ou menacent la culture pourtant prometteuse des macro-algues en prolongeant ainsi les recherches géographiques sur l'algoculture (Tabeaud, 1996). Nous mettrons enfin en pratique cette typologie par l'étude du littoral chinois à l'ouest de la presqu'île de Dalian (Liaoning) et dans le Shandong. 


\section{Présentation générale de l'algoculture à différentes échelles}

\section{Les pays de culture de macro-algues à l'échelle mondiale.}

La production aquacole mondiale se caractérise par un taux de croissance annuel moyen de $6,2 \%$ de 2003 à 2008. Les derniers relevés statistiques de la FAO confirment cette tendance avec 142 millions de tonnes de produits marins capturés ou élevés. La production mondiale des végétaux marins suit la même tendance. 16 millions de tonnes d'algues ont été ainsi consommées dont 15,8 millions issus de l'algoculture pour l'année 2010. 1,25\% des algues consommées sont issues du ramassage côtier sur l'estran ou en mer. La culture mondiale d'algue provient à 99,7 \% d'Asie (15 736141 tonnes en 2010)7.

La Chine domine ce secteur en Asie comme dans le monde. Si l'on se concentre sur les statistiques de l'aire asiatique, on constate l'importance de l'algoculture chinoise. La Chine produit près de 10 millions de tonnes, alors que l'Indonésie, deuxième producteur mondial, comptabilise seulement 2,1 millions de tonnes d'algues cultivées par an, cinq fois moins qu'en Chine (illustration 1). Dans ce classement mondial et régional, les Philippines arrivent en troisième position puis viennent la Corée du sud, le Japon, la Corée du nord. Afin d'illustrer la prépondérance de l'aire régionale asiatique, il est intéressant de noter les quantités produites par le Chili (illustration 1), pourtant grand exportateur d'alginates. À titre de comparaison, la France n'a produit que 35 tonnes de macro-algues -culture et récolte confondues- pour l'année $2010^{8}$ (illustration 1).

11 Si les algues sont cultivées dans l'aire régionale asiatique, c'est qu'elles constituent aussi un aliment largement consommé. Pour comprendre cette géographie de la culture des algues, il faut ainsi prendre en compte le facteur culturel et politique. Récoltées puis cultivées intensivement à partir des années 1960 sous l'impulsion de la politique agricole de la Chine maoïste, elles intègrent plusieurs types de préparations culinaires consommées sous des formes bouillies dans des soupes, fraîches et agrémentées d'une sauce en salade, voire en feuilles séchées pour l'exportation en Asie (feuilles de nori dans les maki et sushi). 
Illustration 1 - Les volumes de macro-algues cultivées et les principaux pays de culture de macroalgues pour l'année 2010

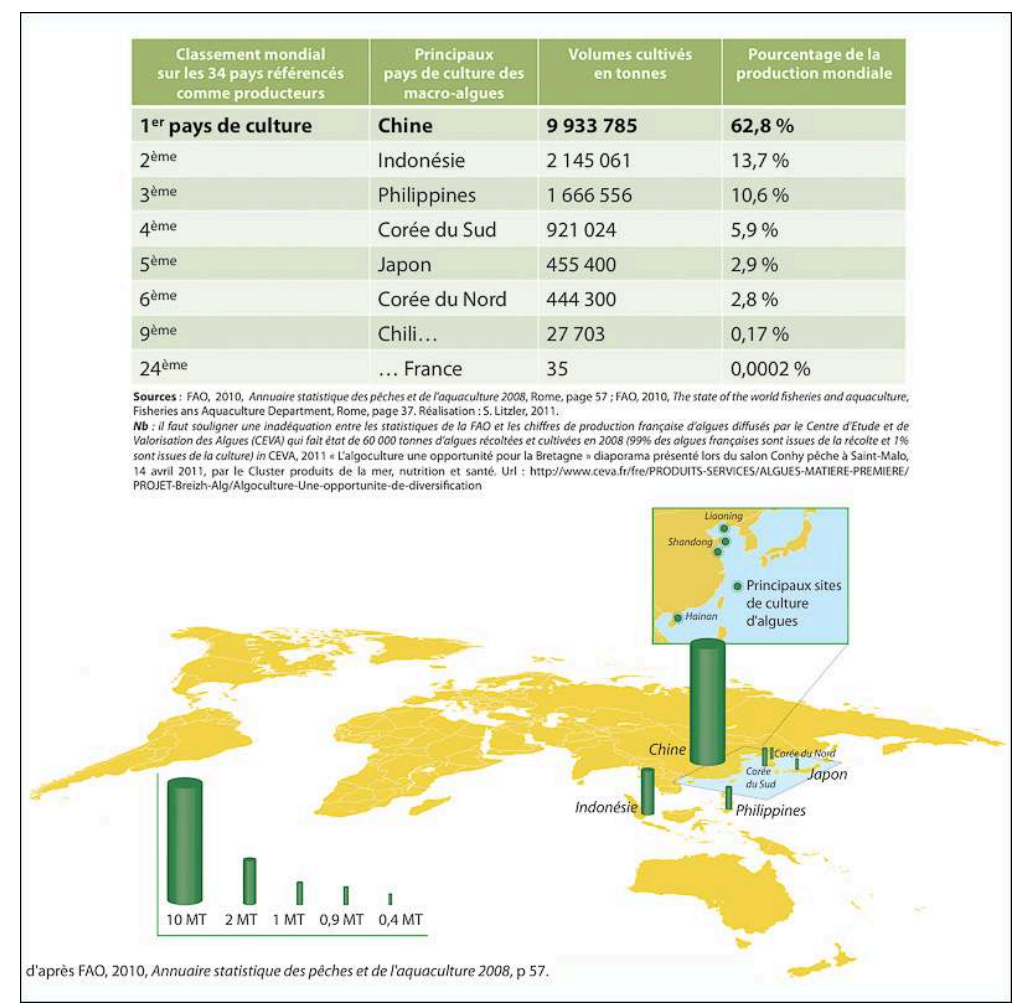

Source : FAO, 2010. Réalisation : S. Litzler, 2011.

\section{Les principales espèces d'algues cultivées en Chine}

Deux grandes familles d'algues sont cultivées en Chine: les brunes et les rouges. Il existe quatre espèces d'algues parmi ces deux familles qui sont cultivées principalement dans les péninsules du Shandong et du Liaoning. Il s'agit de la Laminaria japonica, appelée aussi «kelp», de l'Undaria pinnatifida, connue sous le nom de "wakamé ». Toutes deux sont des algues brunes. Dans la catégorie des algues rouges, le Porphyra Yezoensis, ou "nori", se cultive sur toutes les côtes de la mer jaune, du Liaoning au Jiangsu, alors que la Gracilaria lemaneiformis est cultivée essentiellement dans la partie méridionale de la péninsule du Shandong. Des biologistes chinois ont recensé avec précision les habitats des espèces d'algues se trouvant sur les côtes de la mer jaune. Ils ont classé dix-sept espèces dans l'éco-région de la mer jaune jugées intéressantes pour leurs potentiels alimentaires, pour leur caractère dépolluant pour les eaux aquacoles usées comme pour leurs actifs naturels valorisables en cosmétique (Ding, 2008). L'objectif de ce travail de recensement est aussi d'identifier les espèces endémiques du golfe de Bohai qui, pour certaines, sont en voie de disparition du fait de récoltes excessives. Cette région littorale, qui est à la fois un haut lieu de l'algoculture en terme de volumes produits et de recherches scientifiques menées ${ }^{9}$, est également un environnement littoral fragilisé, surtout par des pratiques de capture et de récolte intensives. L'illustration 2 montre les principales aires de cultures de macro-algues dans le golfe de Bohai. La représentation cartographique juxtapose des espèces le long des côtes, alors que celles-ci sont en réalité présentes sur une frange littorale large d'une vingtaine de mètre à partir du zéro bathymétrique. Notre illustration, qui 
synthétise des recensements de Ding Lanping (Ding, 2008), montre les quatre aires de répartition des principales algues chinoises cultivées. Nous y avons reporté les localisations des villes chinoises du golfe de Bohai où l'algoculture est un secteur d'activité important, Qingdao et Dalian, ainsi que Xingang qui nous servira d'étude de cas. On observe que la Laminaria japonica se cultive facilement dans les eaux froides de la péninsule du Liaoning, son aire de répartition s'étendant vers le Nord. L'algue rouge Gracilaria lemaneiformis préfère en revanche les eaux plus chaudes de la péninsule du Shandong, où ses champs descendent jusqu'à la baie de Jiaozhou au sud de la péninsule. L'Undaria pinnatifida et le Porphyra Yezoensis se caractérisent par une répartition plus homogène de part et d'autre du golfe de Bohai. Près de $66 \%$ de la production totale des algues chinoises sont composées de Laminaria japonica et de Porphyra Yezoensis. Cette extension importante de ces principales espèces d'algues cultivées dans le golfe de Bohai s'explique par les valorisations économiques de ces végétaux marins.

Illustration 2 - Distribution spatiale des principales algues cultivées en Chine du nord

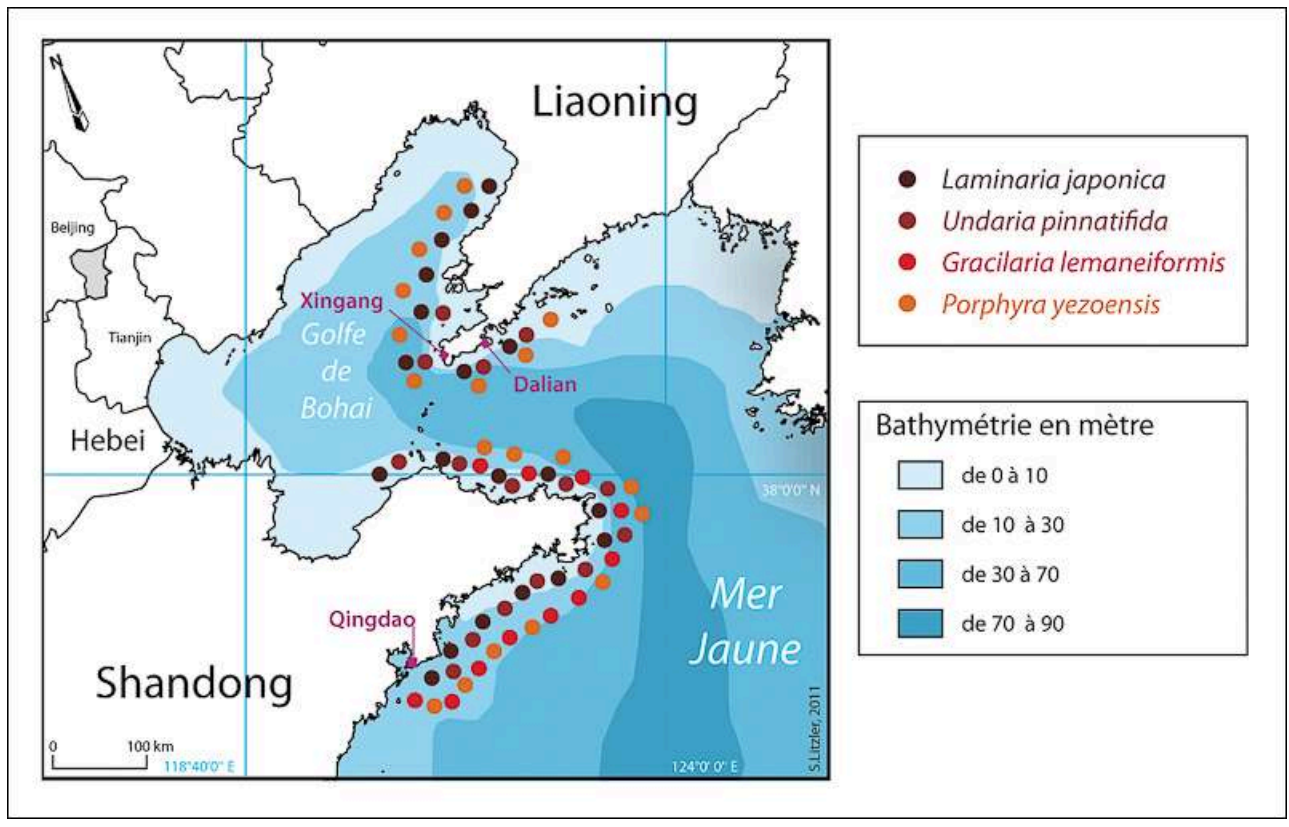

S. Litzler, 2011

\section{Les usages des macro-algues, de la consommation alimentaire directe à l'industrie agro-alimentaire}

Les algues sont un aliment traditionnel dans la culture asiatique. Des études menées par C.K. Tseng, phycologiste chinois et fondateur de l'Institut océanographique de Qingdao, font remonter la première pratique d'algoculture au début de l'an mille sous la dynastie des Song (Neushul, 2000). À Xiamen au sud de la province littorale du Fujian, on releva dans les années 1930 des pratiques culturales ancestrales des communautés locales. Ces dernières ne se contentaient pas de récolter l'algue sur l'estran, mais elles la cultivaient aussi, avec une espèce particulière, la Gloiopeltis furcata, appelée communément le «chicai », pour s'en servir d'aliment, de fourrage animal ou encore d'engrais. Ce n'était toutefois pas une forme de culture intensive comme celle que l'on peut observer aujourd'hui. Ces paysans des côtes littorales pratiquaient une culture par 
sélection : ils frottaient les côtes rocheuses à marée basse avec des couteaux ou des outils en métaux de manière à éliminer toutes les autres espèces d'algues concurrentes poussant sur ces substrats rocheux. La place était ainsi faite au «chicai» qui pouvait croître sur des côtes nettoyées. Dans les années 1950, les recherches des biologistes chinois se poursuivent et parviennent à établir progressivement les mécanismes de reproduction des macro-algues (Chang, Chen, 2008). C'est à partir des années 1960 qu'est engagée une véritable algoculture intensive sous l'impulsion des autorités centrales, réalisée par bouturage sur des cordes de nylon amarrées à des radeaux (illustration 3).

Illustration 3 - La culture des algues brunes et rouges en radeaux, cordes et filets

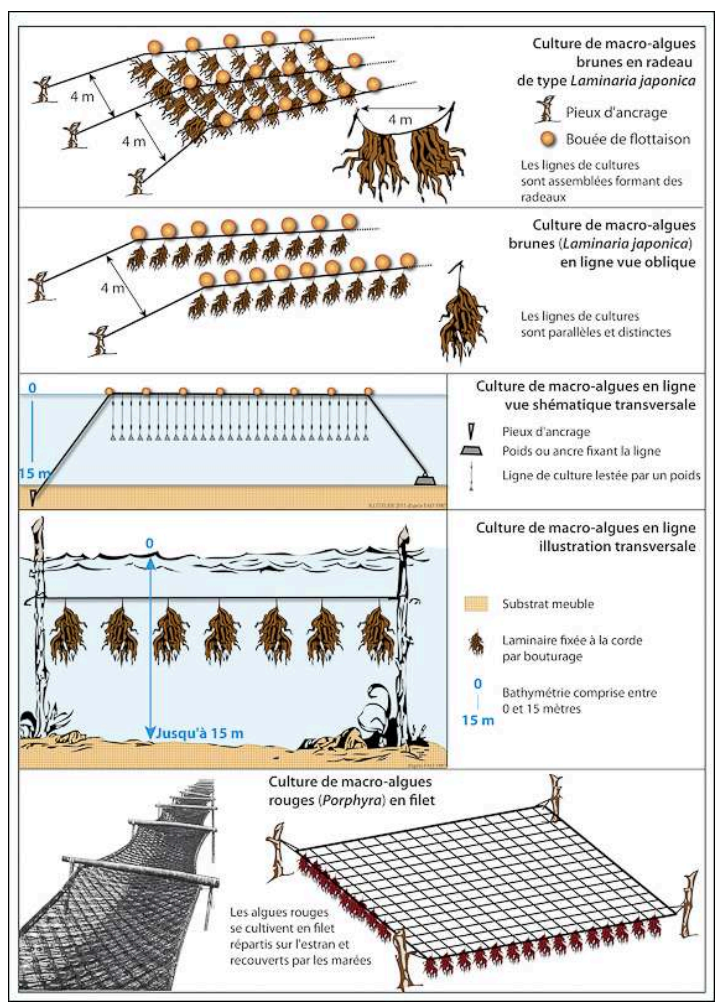

S. Litzler, 2011

Ces macro-algues cultivées ont différents usages. Si l'aire régionale asiatique concentre près de $90 \%$ de la production mondiale de macro-algues, force est de constater que les trois-quarts de cette production sont destinés à la consommation directe sous les différentes formes évoquées précédemment (Leclerc, Floc'h, 2010). Que font alors les asiatiques des $25 \%$ restants? Les macro-algues sont composées de polysaccharides recherchés pour leur propriété visqueuse. Extraites des algues marines, ces substances sont nommées les phycocolloïdes. On les utilise dans l'industrie agro-alimentaire sous les noms d'alginates, carraghénanes et agars (et sous les appellations respectives de E 401, E 407 et E 406). Ces phycocolloïdes sont employés dans de nombreuses préparations agroalimentaires et cosmétiques, desserts lactés, glaces ou dentifrices. Il existe aussi des applications industrielles des alginates dans l'industrie textile pour fixer les couleurs dans les tissus et dans l'industrie papetière. L'industrie chinoise a commencé à exploiter les alginates et les carraghénanes dès le début des années 1930. À Qingdao, ancienne concession allemande, des usines valorisaient les alginates de la 
Laminaria japonica puis de la Sargassum confusum, produisant jusqu'à 10000 tonnes par an pour l'industrie textile. L'importance de la demande a conduit à la mise en culture de ces espèces afin d'alimenter le marché national en alginate. L'exploitation des carraghénanes se situe historiquement plus dans le sud de la Chine, dans l'île du Hainan, où le Betaphycus gelatiniume est valorisé(Tseng, 2004).

La Chine est obligée aujourd'hui d'importer paradoxalement des algues rouges de l'étranger afin de répondre à ses besoins de plus en plus importants.Ces algues rouges importées proviennent essentiellement des Philippines (qui jusqu'en 2009 étaient le premier producteur mondial de carraghénane avec 24000 tonnes exportées pour une valeur de 140 millions d'euros avant de voir leur position remise en cause par la Chine). Comment l'ordre mondial des producteurs de carraghénane a-t-il pu être bouleversé ? Pour le comprendre, il est nécessaire de présenter la filière algacole aux Philippines.Le gouvernement philippin a encouragé la culture des algues dans le sud de l'archipel (île de Mindao) majoritairement de confession musulmane. L'objectif de cette impulsion centrale est double: d'une part résorber la crise sociale et d'autre part lutter contre l'agitation séparatiste. Une industrie algale s'est alors développée du début des années 1980 à la fin des années 1990 jusqu'à assurer en 2009 près de $33 \%$ de la production totale des pêcheries quand ce même secteur génère aujourd'hui environ $2,3 \%$ du PIB philippin. Cette industrie est jugée vitale par une agence gouvernementale philippine, Ressources halieutiques, car elle soutient les économies locales de populations marginalisées. ${ }^{10}$ Or avec l'arrivée des carraghénanes chinois sur le marché mondial, la filière philippine résiste difficilement à des prix d'extraction et de valorisation compétitifs. Les algues cultivées aux Philippines sont rachetées par les Chinois qui les exploitent à l'aide d'une main d'œuvre bon marché et une filière industrielle mieux structurée. Les Chinois sont en mesure de produire des carraghénanes pour approvisionner leur demande nationale puis de les vendre moins chers que les Philippines sur le marché mondial. De plus, des investissements massifs réalisés en Indonésie dans des usines de transformation des algues conduisent à rendre le marché asiatique encore plus concurrentiel.

On constate donc à partir de cet exemple que l'algoculture est une activité importante pour l'aire régionale asiatique. La valorisation des molécules organiques extraites des algues est un secteur dépendant des évolutions des prix mondiaux (la laminarine et le polyphenol se vendent à 500 euros le kilo) ${ }^{11}$, mais participe à l'économie littorale et à la stabilité politique et sociale de ces territoires dont une grande part de la population pauvre trouve dans la culture des algues un moyen complémentaire de subsistance. Les algues sont donc une denrée alimentaire comme les autres dans un marché libéral et spéculatif ${ }^{12}$ comme un facteur d'équilibre social dans la mesure où elles garantissent un minimum vital pour des populations insulaires défavorisées ${ }^{13}$. Les mutations de la filière et les dynamiques mondiales et régionales de la culture de macro-algues étant importantes, il convient désormais de dégager les contraintes géographiques de cette activité déterminantes pour son développement, en se concentrant sur la culture algale du golfe de Bohai en Chine. 


\section{Les différentes contraintes géographiques de l'algoculture}

17 Nous cherchons à définir et à classer l'ensemble des contraintes naturelles et des contraintes anthropiques. Pour les contraintes d'origine naturelle, climatique et environnementale, il faut tenir compte des aléas météorologiques, identifier des données bathymétriques, analyser la nature des substrats en fond de baie et s'attacher à l'étude des courants marins. Pour les contraintes d'origine anthropique, les phénomènes d'eutrophisation des baies maritimes, la diffusion des pollutions industrielles et urbaines dans les zones côtières et les conflits d'usages entre acteurs sont autant d'éléments pouvant limiter l'activité algacole. Cette approche générale est illustrée par un bloc-diagramme de synthèse (illustration 4).

Guang-Ce Wang, chercheur à l'Institut Océanographique de Chine a précisé les huit étapes du système moderne de culture scientifique des macro-algues pour les deux algues importées au XXe siècle : la Laminaria japonica du Japon et l'Undaria pinnatifida de Corée. Les recherches agronomiques d'Etat dans les années 1950 établirent les conditions de base de la production algacole : 1 . l'ensemencement 2 . les substrats de culture, 3. les conditions d'ensoleillement (intensité et régularité) 4. la température, 5. les nutriments inorganiques, 6 . le choix des espèces aux conditions, 7. les agents pathogènes, 8 . la sélection des espèces et les nouvelles souches ${ }^{14}$.

Illustration 4 - Bloc diagramme de la culture en mer de macro-algues en Chine

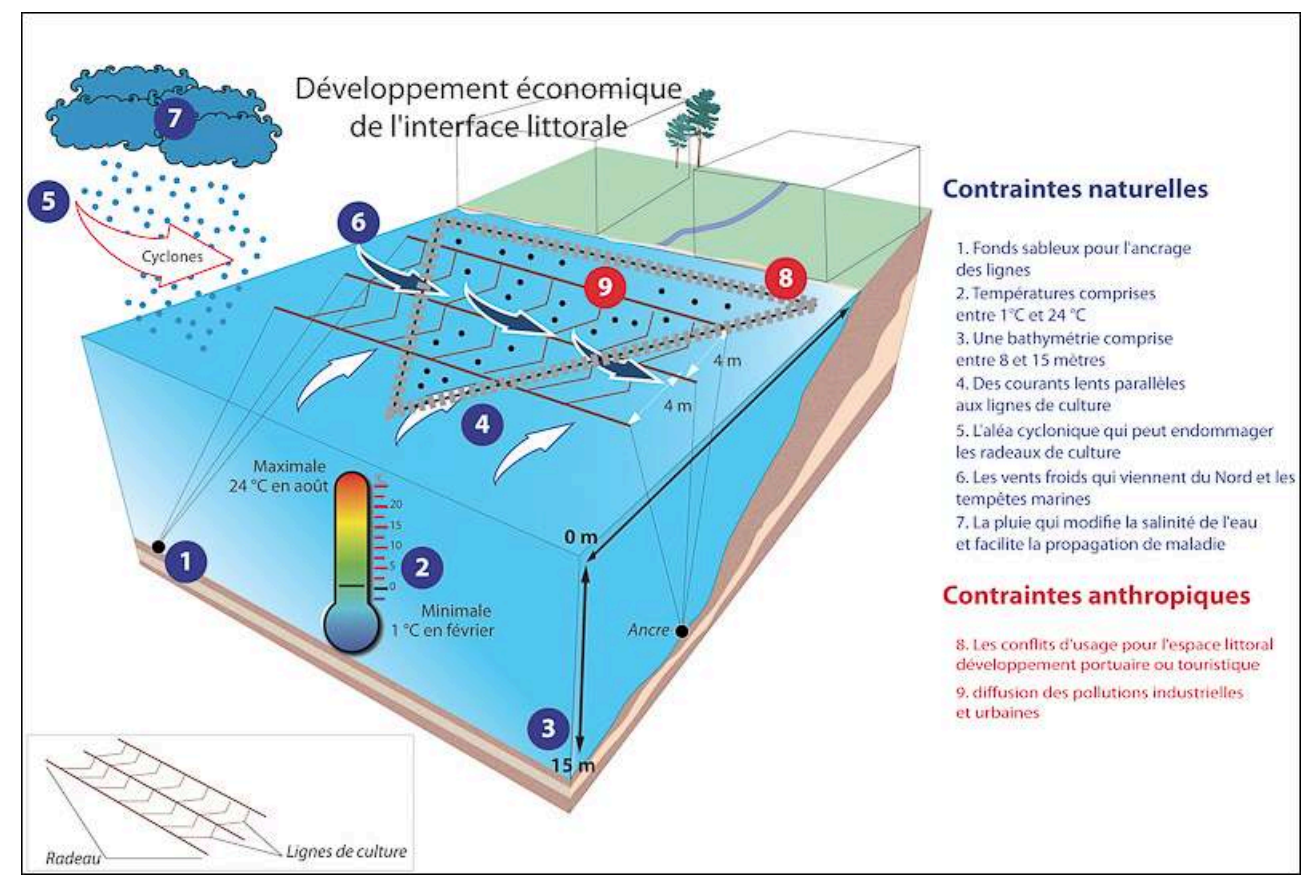

S. Litzler, 2011.

\section{Les contraintes naturelles pour la production algacole.}

19 La culture des macro-algues brunes comporte trois étapes : il y a d'abord un stade en écloserie à l'abri des intempéries et des prédateurs pour la fécondation des spores. La 
seconde étape est la germination et la croissance des plantules. Lorsque celles-ci ont atteint quelques centimètres de long, elles sont transférées dans un troisième temps en mer et fixées à des cordes (illustrations 3-4) (Leclerc, Floc'h, 2010). Ces cordes doivent être solides pour assurer le poids des algues qui peuvent atteindre à la fin de leur croissance une longueur de trois à quatre mètres. Ce mode de culture respecte le double rythme de croissance des laminaires : une première croissance qui commence en hiver et une deuxième phase de croissance à la fin de l'été (de Reviers, 2002). Ces cultures en ligne sont rassemblées en radeaux, sensibles aux vagues hautes et aux intempéries. Les algues rouges de type Porphyra sont cultivées sur des filets tendus sur la mer (illustration 3). Ces modes de cultures (lignes-cordes-filets) doivent être situés dans des baies abritées (illustrations 6 à 11) dont certains critères bathymétriques et météorologiques doivent être respectés afin d'obtenir des rendements optimaux (2000 lignes de cultures par hectare en mer).

Les premières contraintes naturelles sont la nature du sol marin et la turbidité de l'eau; il faut privilégier les fonds sableux et non pas rocheux, car il est plus facile d'ancrer les radeaux de culture dans un substrat meuble. Pour fixer les radeaux au fond de la baie, il faut choisir des eaux peu profondes, sachant qu'au-delà de quinze mètres de profondeur la photosynthèse est insuffisante, trop peu de lumière atteignant pas les thalles de l'algue ; en deçà de 8 mètres, la lumière peut être trop forte et nuire à l'algue (illustration 4). De la même façon, il faut prendre en compte la turbidité de l'eau: une eau opaque nuit à la photosynthèse et diminue les rendements de culture (Fang, 1996 ; Chang, Chen, 2008).

21 Les données météorologiques sont essentielles: les tempêtes tropicale de la partie méridionale de la Chine peuvent détruire les fragiles radeaux de culture, notamment dans les provinces aquacoles du littoral du Sud-Est, au Zheijiang, au Fujian, au Guangdong et au Hainan. À l'inverse les vents froids provenant de Sibérie et de Mongolie conjugués aux vents d'hiver peuvent occasionner des vagues hautes de 4 à 5 mètres dans les baies aquacoles du golfe de Bohai fragilisant ainsi les espaces côtiers de culture (Zhang, Rørtveit, 2004). Les fortes pluies d'hiver sur l'estran dans la partie septentrionale de la Chine modifient la salinité des eaux de baie. Cela peut avoir des conséquences sur la croissance des algues car une modification de la salinité des eaux de culture peut d'une part favoriser la propagation des maladies et d'autre part entraîner la disparition des laminaires (de Reviers, 2002 ; Troell, 2008).

Les températures marines constituent aussi un critère supplémentaire à évaluer; les eaux ne doivent pas être inférieures à 1 degré en hiver ou gelées trop longtemps car cela fragilise les jeunes thalles qui sortent de l'écloserie; les eaux ne doivent pas dépasser les 26 degrés en été sous peine de nuire à la croissance des algues (Duarte, 2003). C'est pour cela que le golfe de Bohai et la péninsule du Shandong constituent la principale zone de culture de macro-algues: ils sont situés aux environs du $38^{\circ}$ parallèle nord et leurs eaux côtières répondent à l'ensemble de ces critères de température et de climat (illustration 2).

23 Les courants marins sont aussi un facteur important à considérer pour une culture optimale. Ces courants doivent être le plus possible parallèles aux lignes de culture, afin d'éviter par exemple que les longues thalles ne s'entremêlent lorsqu'elles atteignent leur stade final de croissance (illustrations 3et 4). Les courants les plus favorables sont ni trop lents ni trop rapides pour faciliter l'absorption des nutriments par les algues. Un courant régulier parcourant en moyenne de 10 à 50 centimètres par 
seconde est idéal pour assurer la croissance des algues (Fang, 1996). Notre blocdiagramme offre une vue schématique de toutes ces contraintes naturelles. Nous y avons juxtaposé les contraintes d'origine anthropique dont nous verrons l'importance croissante (illustration 4).

\section{Les contraintes anthropiques et la pollution littorale}

24 Les meilleurs territoires pour la culture des algues se situent dans les baies lumineuses, sableuses, de faible profondeur et protégées des courants marins et des tempêtes atmosphériques. Si l'algoculture et l'aquaculture se sont installées depuis les années 1960 dans ces espaces marins, la diffusion des polluants industriels dans les eaux côtières (comme au delta du fleuve Jaune) ont fait parallèlement du golfe de Bohai une des mers semi-fermées les plus polluées du monde (illustration 5). D'une part cette pollution conduit à des phénomènes récurrents d'eutrophisation; d'autre part les polluants charriés par les fleuves se retrouvent dans les algues brunes qui peuvent devenir impropres à la consommation humaine (Leclerc, Floc'h, 2010). L'accumulation des sédiments charriés par les fleuves (Yangzi, fleuve Jaune) augmente enfin la turbidité des eaux côtières, ce qui constitue par exemple un obstacle à la photosynthèse des algues et fragilise leur croissance.

Selon le rapport 2010 sur la qualité de l'environnement océanique en Chine ${ }^{15}$, les risques sanitaires des productions marines s'aggravent: les niveaux enregistrés de la pollution chimique, de pollution par des matières organiques et de pollution par les métaux lourds (plomb, cuivre, mercure, cadmium) des côtes chinoises et principalement des estuaires atteignent des niveaux inquiétants (illustration 5). Audelà du fait que la pollution chimique des eaux côtières réduit la productivité de l'algoculture, le manque de suivi des contrôles sanitaires sur les productions de cultures marines côtières a pour conséquence une commercialisation des algues et de l'ensemble de la production aquacole dépassant souvent les concentrations maximales de certains polluants. De même que dans les huit embouchures de la rivière des Perles (Guangdong) les coquillages concentrent les polluants dus aux rejets (la plupart du temps clandestins) des industries chimiques dans les eaux littorales ${ }^{16}$, le golfe de Bohai connaît une situation sanitaire de ses eaux maritimes semi-fermées " entre mauvaise et médiocre", préjudiciable aux cultures marines: l'étroitesse de son ouverture océanique, sa faible bathymétrie et les embouchure de grands fleuves pollués (le Huanghe dans le Shandong, le Luanhe dans le Hebei et le Shuangtaizihe dans le Liaoning) concentrent la pollution dans la baie et contaminent les cultures marines et la production aquacole (illustration 5).

Avant même les deux marée noires récentes, une cartographie précise de l'Office national des affaires maritimes (State Oceanic Administration ou SOA) avait déjà montré en 2008 l'étendue de la pollution des zones de mariculture du golfe de Bohai ${ }^{17}$ : toujours selon cette administration, $22 \%$ des eaux marines sont polluées en 2010 contre seulement $14 \%$ en $2005^{18}$.Les prélèvements effectués depuis 2007 aux embouchures du Shuangtaizihe, du Luanhe et du Huanghe montrent un état sanitaire « invariablement médiocre " entraînant une pollution des deux grandes baies de la mer de Bohai : la baie de Laizhou (Shandong) et la baie de Jinzhou (Liaoning). Sur les 18000 kilomètres du littoral chinois, l'essentiel des concentrations des polluants littoraux se trouve ainsi en Chine du nord, alors même qu'elle est le lieu majeur des productions marines, de 
l'algoculture et des fermes conchylicoles (illustration 5). L'agriculture marine doit faire face à la diffusion littorale des polluants terrestres et aux nouveaux risques de « marées rouges " toxiques et les « marées vertes ", dont la plus symbolique est à ce titre celle de la baie de Qingdao par l'ulva prolifera à l'été 2008 au pied même de l'Institut océanographique de Qingdao.

Illustration 5 - Pollutions et poldérisation dans le golfe de Bohai, principaux risques pour les cultures marines

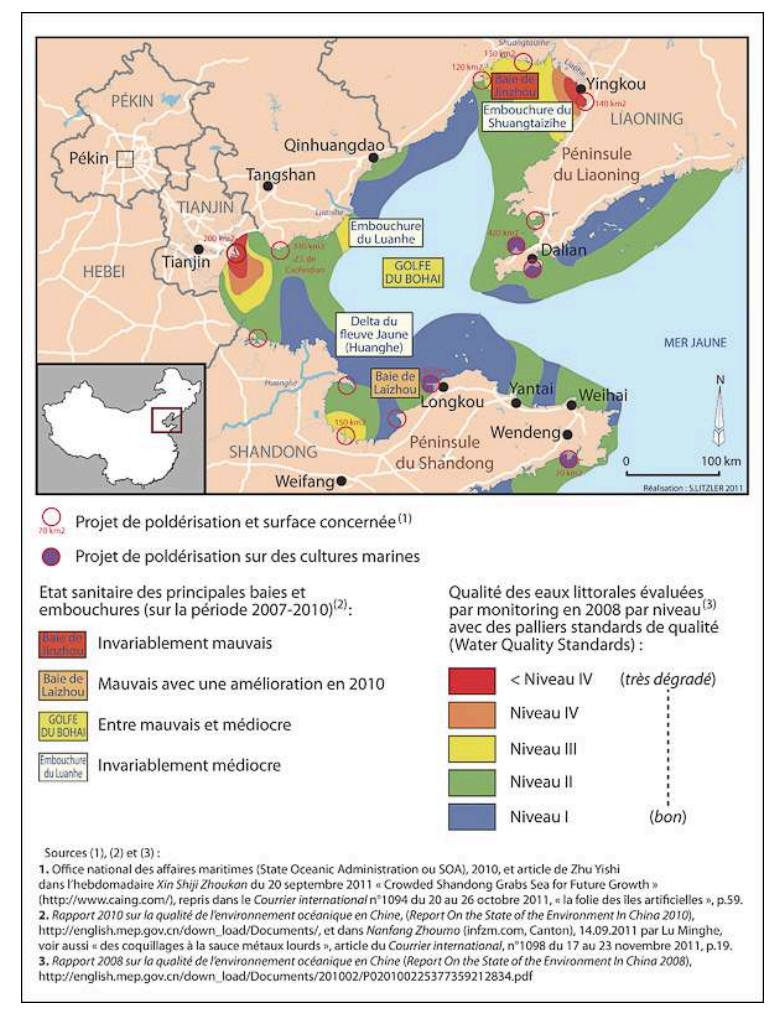

S. Litzler, 2011.

\section{Les conflits d'usages sur le littoral et la poldérisation menacent des espaces de cultures marines}

Les concurrences des espaces littoraux remettent aujourd'hui en cause les cultures marines. Une poldérisation massive des côtes du golfe de Bohai (illustration 5) et de la mer Jaune vise à étendre les villes et concentrer les zones industrielles sur la mer. Les îles proches du littoral sont généralement rattachées à la côte comme le montre notre schéma du sud de Dalian et ce que permet d'évaluer les images satellites sur la durée (de 2003 à 2011 et illustration 6). 


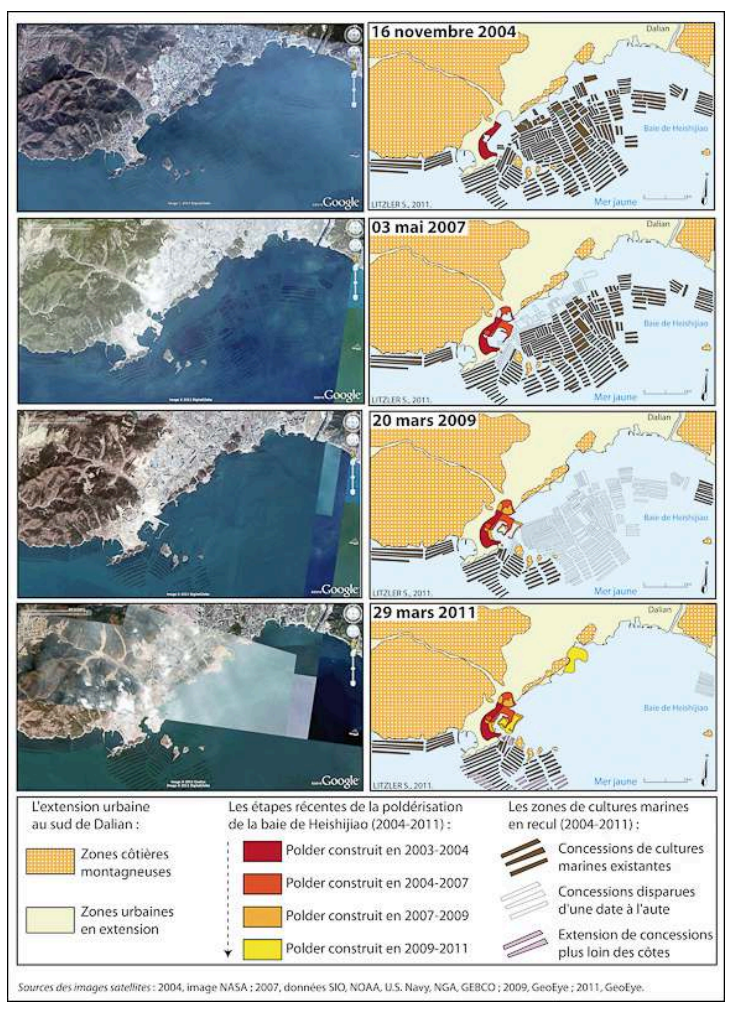

S. Littzler, 2011.

Par un chapelet d'îles artificielles, l'organisation des cultures littorales est profondément modifiée : celles-ci sont déplacées, réduites ou supprimées. Il est à rappeler que ces îles côtières naturelles fournissent ici des zones d'abri optimales pour l'algoculture. La modification artificielle du trait de côtes provoque un recul progressif des certaines concessions marines. Dans un contexte d'accélération de la poldérisation en Chine avec 13000 hectares gagnés sur la mer en 2010 selon l'office national des affaires maritimes, les 3400 kilomètres de côtes du Shandong ( $18 \%$ des côtes chinoises) sont investis prioritairement depuis 2010 par le "programme national de développement économique maritime» qui mobilise les pouvoirs politiques et les promoteurs du littoral. Le développement du Shandong, province de près de 100 millions d'habitants, engendre un besoin contemporain de nouvelles zones industrielles, résidentielles et commerciales en évitant dans la mesure du possible les expropriations agricoles (les terres agricoles étant d'ailleurs davantage protégées). Grâce à la faible profondeur du golfe de Bohai et la grande quantité de sédiments disponibles, la poldérisation y est rentable, sans expropriation, ni conflits ou risque politique local, ce qui explique l'importance des travaux actuels; en témoigne la nouvelle zone d'industries marines de Longkou (Shandong), débutée en octobre 2010, avec un comblement de plus de $35 \mathrm{~km}^{2}$ de mer d'ici à 2014 ${ }^{19}$ (illustration 5).

L'Office national des affaires maritimes estime que ces remblais sur $550 \mathrm{~km}^{2}$ du golfe ont réduit par aplanissement le littoral de $260 \mathrm{~km}$, sacrifié une grande partie des zones humides (actives dans l'équilibre et la dépollution des écosystèmes littoraux), modifié artificiellement les courants marins côtiers et la sédimentation, ralentissant à terme le renouvellement des eaux du golfe. 
Face à ces contraintes naturelles et anthropiques, le développement des recherches chinoises sur le génome des macro-algues tente d'adapter les algues par modification génétique et d'améliorer leur photosynthèse et leur résistance aux conditions climatiques et aux pollutions. Les macro-algues deviennent un objectif des nouvelles orientations agronomiques par les généticiens internationaux. Face aux difficultés des recherches génétiques sur les micro-algues et l'absence actuelle de rentabilité, la recherche génétique s'étend simultanément sur les macro-algues. Aux dernières conférences internationales, dont Alg'n'Chem en novembre 2011, certains des principaux chercheurs de l'IFREMER ne cachent plus publiquement leur inquiétude d'une mise en culture marine d'algues OGM en Chine, et ceci depuis quelques années, sans étude publique d'impact environnemental et sanitaire, sans concertation internationale et sans transparence.

Les sites de l'algoculture chinoise (illustrations 2 et 7) sont enfin des lieux avec des qualités paysagères : les baies protégées, sableuses et ensoleillées commencent à devenir des espaces attractifs pour une population chinoise de plus en plus tournée vers un tourisme littoral et de plage. Du fait d'un usage touristique accru du littoral chinois se développent des phénomènes de concurrence pour l'espace dont les administrations provinciales ont pris conscience; si le tourisme, l'industrie, l'expansion urbaine et les aménagements portuaires consomment davantage cet espace littoral, il est fort probable que la question des conflits d'usages s'aggrave au sein des politiques d'aménagement (Zhang, Rørtveit, 2004). Nous souhaiterions à ce propos illustrer en dernière partie cette question des concurrences spatiales sur le littoral chinois grâce à l'exemple de la ville de Xingang (Liaoning).

Illustration 7 - Vue en perspective oblique est-ouest du littoral de la Chine du nord présentant les zones de cultures d'algues

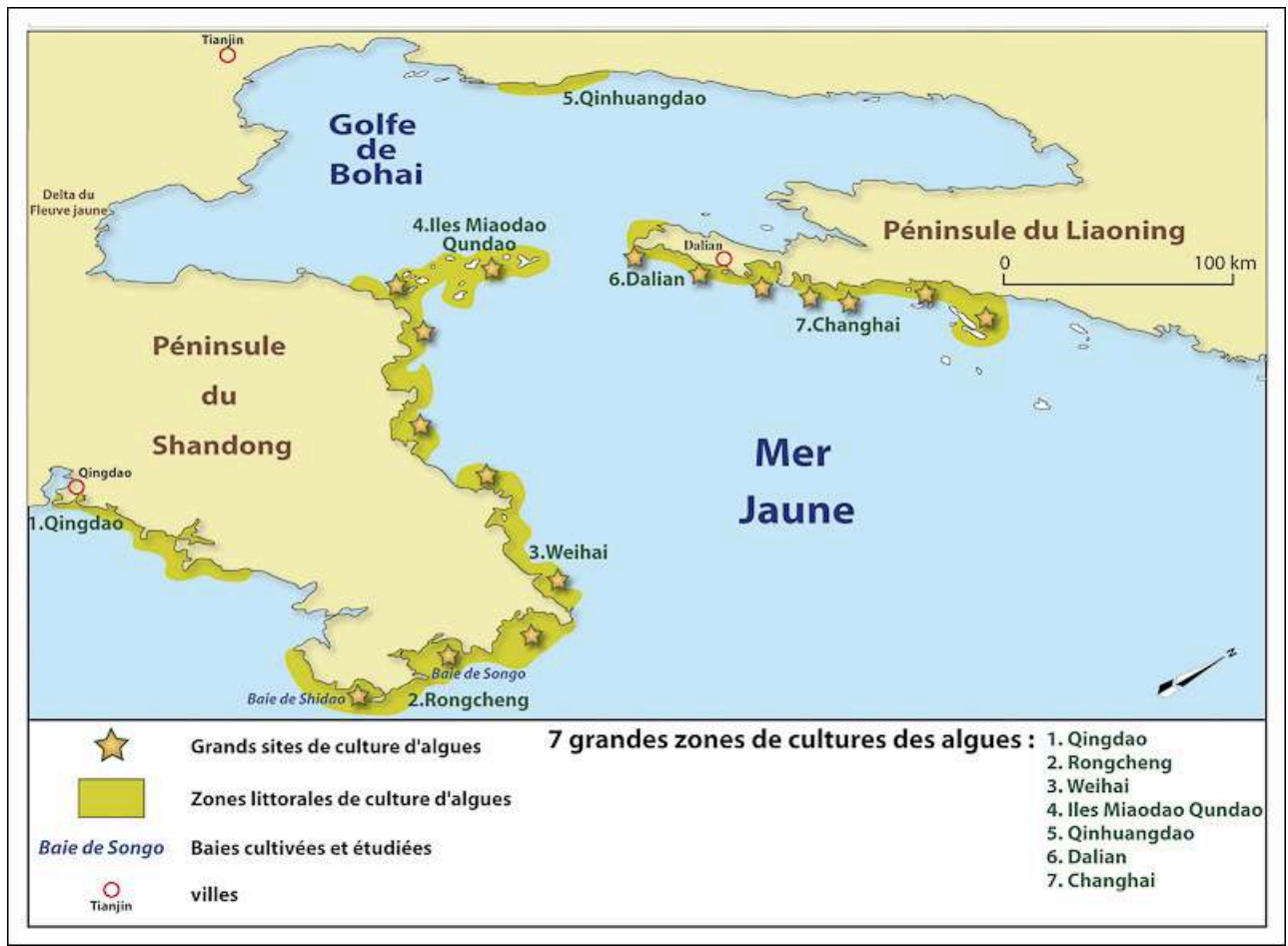

S. Litzler, 2011. 


\title{
Les évolutions de la culture des algues en Chine
}

\author{
Étude de cas d'un recul des concessions algales face à la \\ littoralisation des activités en Chine : le choix du développement \\ portuaire à Xingang (Liaoning)
}

Xingang est un port située à $50 \mathrm{~km}$ à l'ouest de Dalian (Liaoning) qui a connu sur les dix dernières années une croissance spatiale et économique importante. L'image satellite est un outil utile qui permet de saisir les évolutions du tissu urbain sur la durée. La presqu'île de Dalian produit $80 \%$ des algues brunes chinoises en raison des nombreuses baies et de la qualité des eaux (Chang, Chen, 2008). Les deux images satellites juxtaposées en illustration 8 montrent toutefois une donnée géographique nouvelle qui influe sur la mariculture et l'algoculture. Sur celle du haut, prise le 18 septembre 2004, on peut apercevoir des bandes noires étroites échelonnées parallèlement en arc de cercle dans la baie. Il s'agit des radeaux de culture. Le site est ici favorable à la culture des algues : une baie protégée, des eaux peu profondes et des eaux froides qui assurent la croissance des algues. C'est un tout autre aménagement que nous montre l'image satellite du bas datant du 12 mai 2010 : les concessions algacoles ont disparu, des terrespleins ont été construits dans la baie modifiant le trait de côte. Des bâtiments portuaires, une grande zone industrielle, un chantier naval et des maisons individuelles ont transformé le tissu urbain de Xingang.

La géographie de Xingang a donc changé de nature : d'une baie à vocation aquacole et agricole reliée au marché intérieur, elle s'est muée en une façade portuaire industrielle ouverte en lien avec le dynamisme du pôle de Dalian (illustrations 8 et 9), à l'image de l'essor économique de la façade littorale chinoise dans une ancienne région industrielle depuis longtemps ouverte sur le monde. On peut repérer sur le littoral chinois la répétition de cette situation: le développement rapide des interfaces littorales (Sanjuan, 2007) peut à terme fragiliser les concessions algacoles malgré la politique de développement de la mariculture sur l'espace marin littoral encore disponible. 
Illustration 8 - Images satellites comparées de Xingang

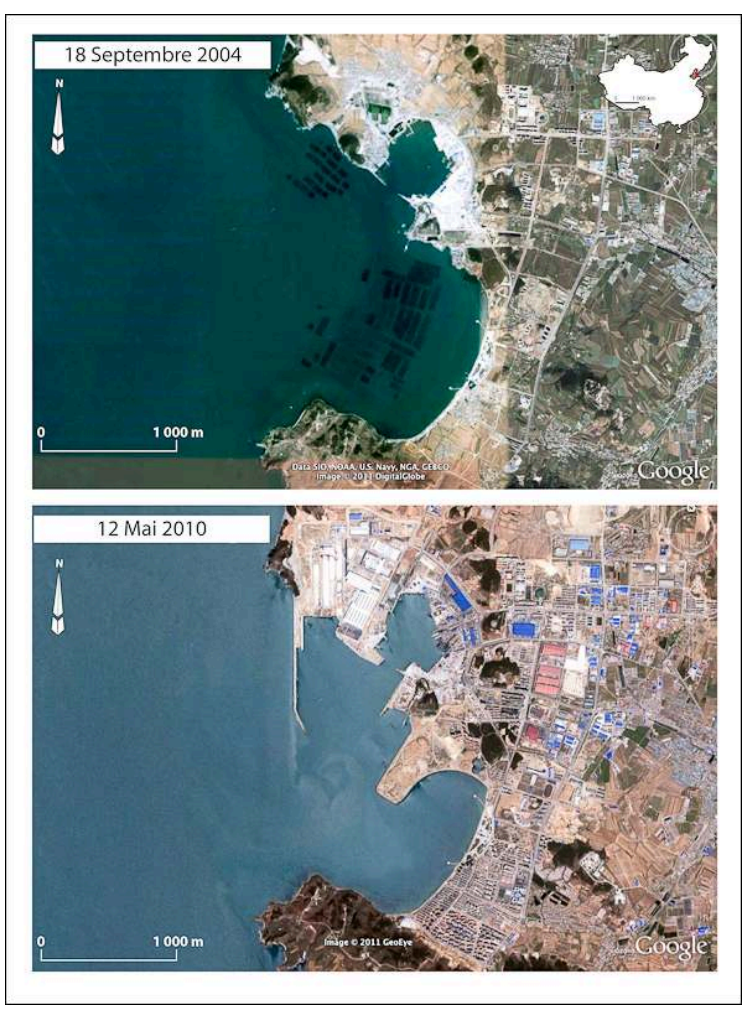

Source : Google.

Illustration 9 - Xingang : la disparition de l'algoculture au profit du développement portuaire
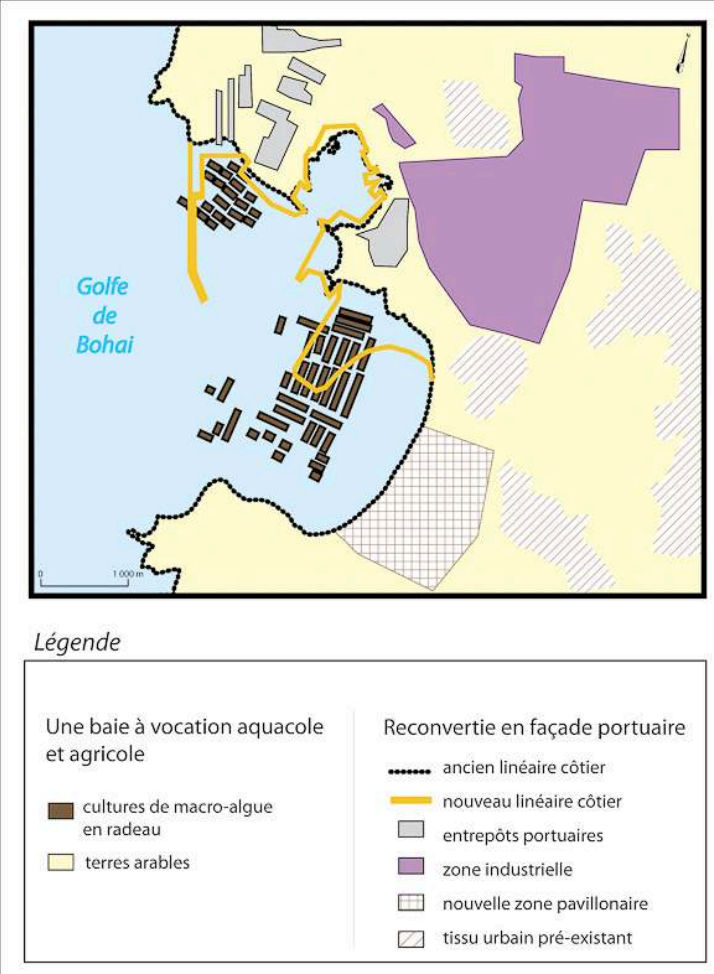

S. Litzler, 2011. 


\section{Les perspectives d'évolution de l'algoculture chinoise dans le développement d'une aquaculture intégrant les productions marines}

34 Au-delà du fait que l'algoculture des eaux côtières chinoises subit les pollutions industrielles et urbaines, il convient de rappeler que la mariculture intensive ellemême a des effets indésirables sur les écosystèmes ${ }^{20}$.

La production d'algues (dont essentiellement la Laminariajaponica) composait de 50 à $60 \%$ de la mariculture chinoise jusqu'au début des années 1980. La diversification des espèces et la croissance rapide de la production de mollusques, de poissons et de crevettes posèrent le problème de leur complémentarité pendant la croissance rapide des productions (production multipliée par 9 de 1985 à 2001). La conquête agricole de l'estran s'est accélérée selon un rythme annuel moyen de $10 \%$ depuis 1985 passant de 300000 ha à plus de 1300000 ha utilisés sur la mer depuis les années 2000. Le littoral chinois est une nouvelle " frontière » de conquête agricole avec 13 millions d'hectares de zone maritime de bathymétrie inférieure à $20 \mathrm{~m}$ de profondeur.

La densification des fermes marines, tout comme la pollution croissante des eaux littorales depuis le milieu des années 1990, a favorisé la transmission des maladies et des agents pathogènes et une compétition excessive des cultures et des espèces pour les nutriments.Les effets de la mariculture nuisent durablement à la culture des algues. C'est un axe fondamental des études littorales chinoises portées par l'Institut de recherches maritimes de la mer Jaune (The Yellow Sea Fisheries Research Institute) de Qingdao et cofinancées par le fonds de développement des Nations Unis (UNDP/GEF Yellow Sea Large Marine Ecosystem Project).

L'algoculture est une des composantes de cette « révolution de la mariculture » car les agriculteurs marins chinois cultivent de plus en plus plusieurs espèces d'animaux et végétaux marins sur les mêmes sites. C'est ainsi qu'abalones, poissons, huîtres et kelp (laminaires) grandissent ensemble. Les algues se nourrissent des nutriments provenant des coquillages. À leur tour, elles filtrent et oxygènent les eaux de culture contribuant à la santé des autres espèces marines (illustration 12). Les scientifiques chinois travaillent depuis une quinzaine d'année sur les espèces compatibles dans les eaux de culture; nous pouvons ici souligner l'intérêt de deux études portant sur les détails techniques de la culture de la Gracilaria lemaneiformis et de la Laminaria japonica avec la bi-valve Chlamys farreri (Fang, 1996 ; Yuz, 2009). L'Institut océanographique de Qingdao, en collaboration avec l'Académie chinoise des sciences, a conclu après trois semaines d'expérience que la Gracilaria absorbait efficacement l'ammonium et le phosphore issus des excrétions des bi-valves. Cette algue rouge est une espèce prioritaire pour une aquaculture intégrée multi-trophique (A.I.M.T ou Integrated Multi-trophic Aquaculture, IMTA, illustration 12) (Yuz, 2009). Si les scientifiques chinois se posent la question de l'aquaculture intégrée, c'est qu'ils ont constaté une baisse récente de leur rendement en raison de maladies touchant toutes les espèces (abalone, kelp, poisson, bi-valve). En 30 ans, la production est passée de 150000 tonnes d'algues brunes produites en 1973 (Lucas, 1980) à près de 1,2 million de tonnes (Chang, Chen, 2008). Cette culture intensive soulève de nombreuses interrogations sur la qualité environnementale des eaux consacrées à la mariculture et sur les conséquences environnementales de cette production intensive, moins innocente qu'elle ne parait et que beaucoup soutiennent. 
De nouveaux modes de production sont ainsi mis à l'essai : abris anti-tempêtes, nourrisseurs automatiques et capteurs environnementaux (Chang, Chen, 2008). Ces solutions techniques peuvent être couplées avec la pratique de la polyculture (illustration 12). La baie de Songo fournit à ce titre un des exemples d'aquaculture multi-trophique intégrée car les algues, les abalones, les poissons sont cultivés ensemble sur une surface s'étendant jusqu'à $8 \mathrm{~km}$ du rivage (Troell, 2008 . illustrations 10 et 11). La mariculture intégrée constitue une alternative prometteuse pour lutter contre la pollution issue d'une monoculture intensive (Troell, 2003). L'aquaculture pourrait à moyen terme devenir une source essentielle d'approvisionnement en protéine animale; c'est pourquoi elle tente de relever le défi de l'intensification des rendements tout en préservant les eaux marines. Des modélisations ont été réalisées à cette fin: l'étude des courants marins et de la bathymétrie dans la baie de Songo a permis de construire plusieurs scénarios de distribution spatiale des espèces cultivées (illustrations 10 et 11). L'objectif de ce travail modélisateur est d'évaluer la capacité de charge de la baie et de faciliter la diffusion des nutriments entre les algues et les coquillages pour optimiser les rendements et épurer naturellement les eaux (Duarte, 2003).

Illustration 10 - Bathymétrie de la baie de Songo

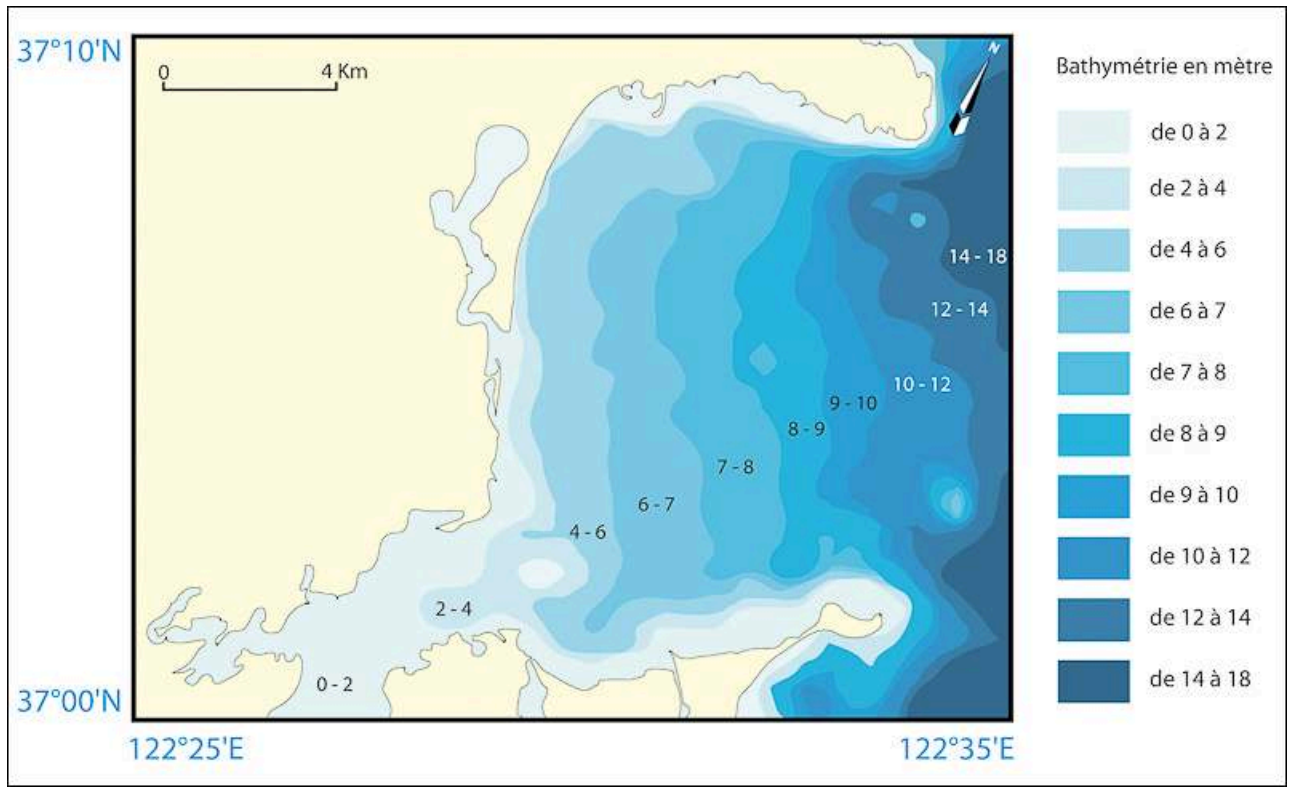




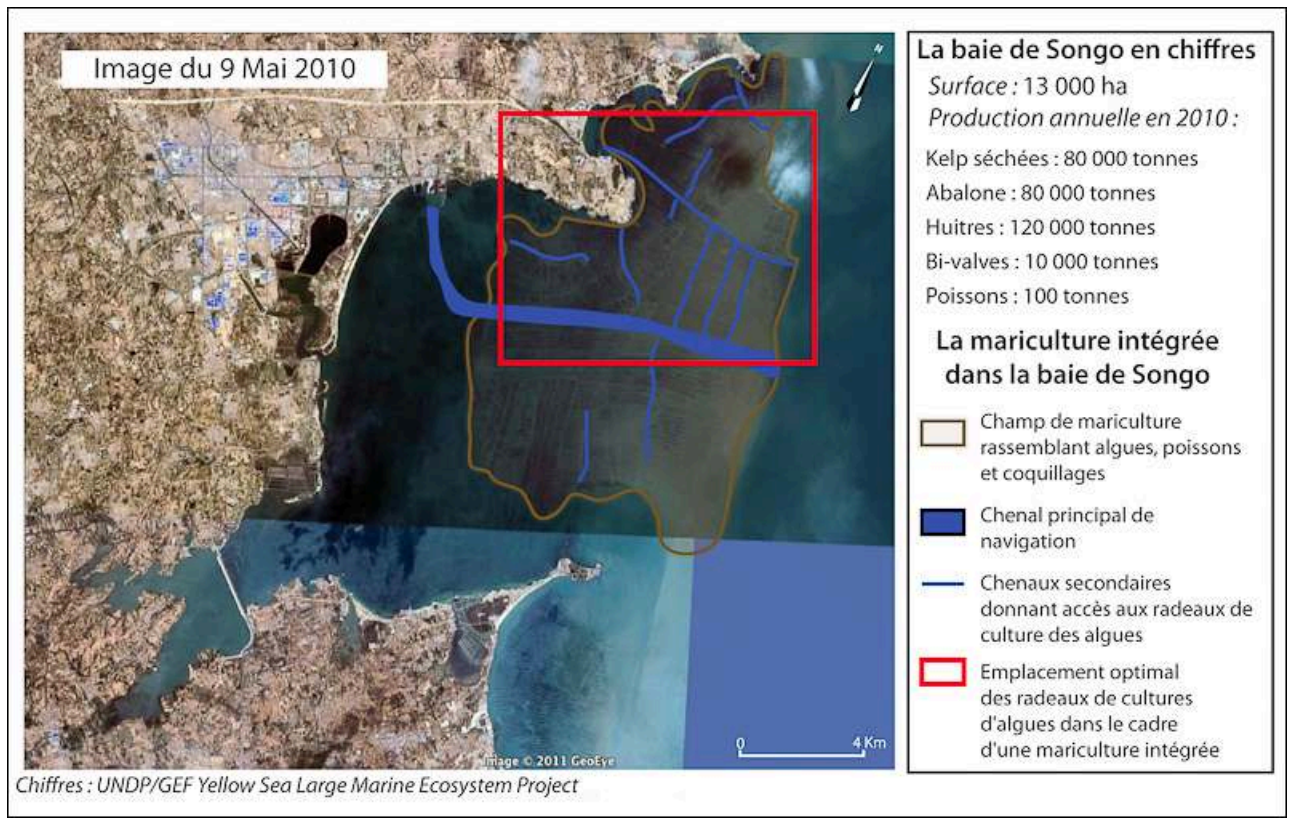

Illustration 12 - Système de mariculture multi-trophique intégrée et circulation des nutriments dans le modèle chinois

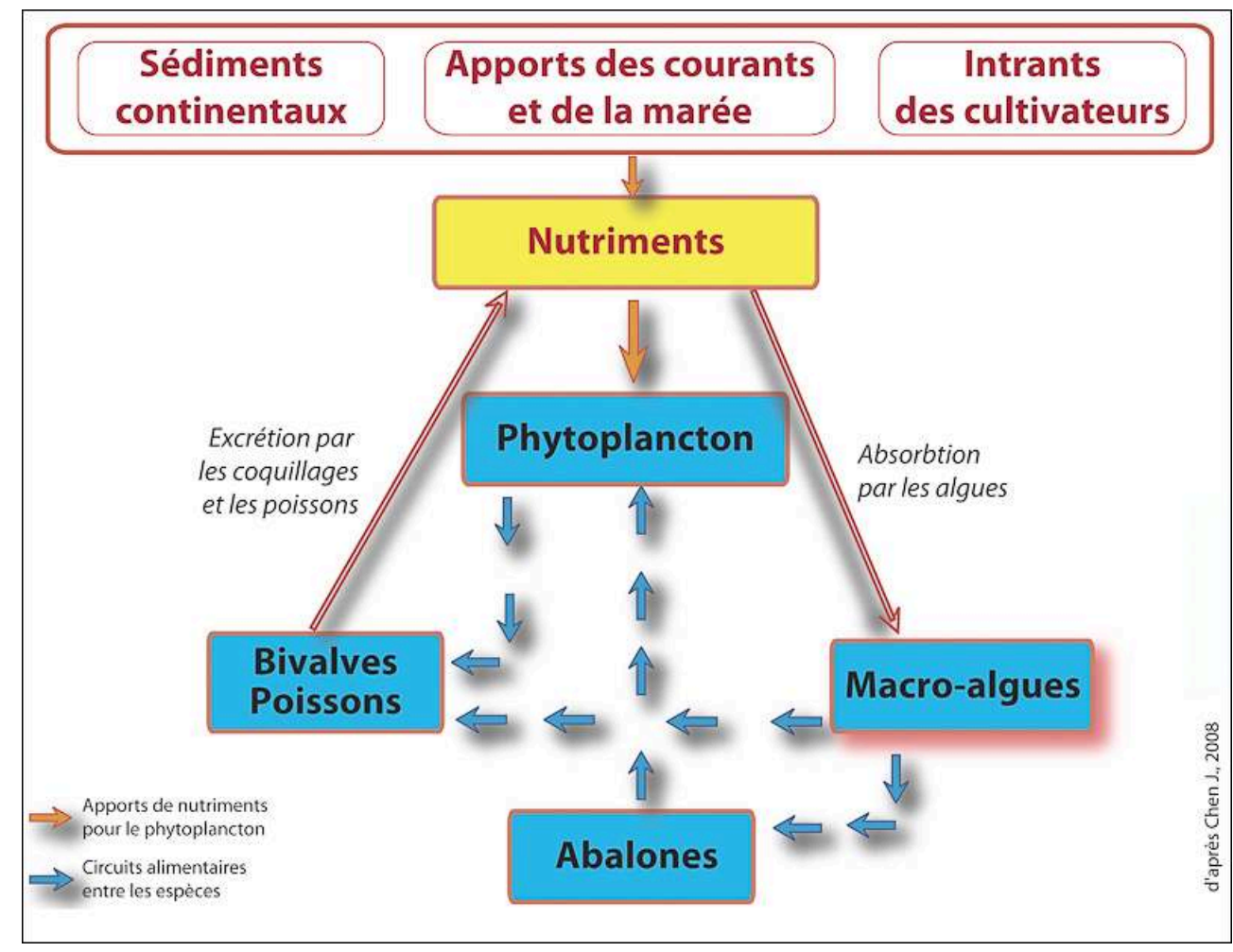

La situation de l'aquaculture chinoise mérite notre attention à plus d'un titre: d'une part c'est un modèle productif exportable et reproductible sur un des rares espaces agricoles de conquête et qui est de plus en plus investi ; d'autre part les eaux aquacoles françaises sont aussi confrontées à la pollution et à la diffusion de pathologies affectant principalement la filière ostréicole et conchylicole. 


\section{Un nouveau modèle chinois de mariculture intégrée exportable?}

entreprises bretonnes cultivant l'Undaria pinnatifida, il n'existe pas de larges concessions marines où les macro-algues seraient cultivées en ligne dans des proportions que l'on retrouve en Asie. Pourtant les algues pourraient constituer une des réponses écologiques et économiques aux difficultés récurrentes que connaissent actuellement les filières ostréicole et conchylicole françaises. À ce titre une étude de faisabilité de culture d'algues en ligne a été menée ces deux dernières années sur plusieurs sites expérimentaux littoraux bretons comme le projet CHACO. Il constitue le volet technique d'un programme plus large appelé Breizh'alg. Ce dernier bénéficie de l'expertise du CEVA (Centre d'étude et de valorisation des algues). Il s'agit d'étudier la culture de deux espèces de macro-algues (Undaria pinnatifida et Saccharina latissima) suivant différents modes de culture et en augmentant la surface des espaces algacoles de façon à atteindre une masse critique de production (60 ha en 2011, 1000 ha en 2015). Pour le responsable du pôle "Algues Produits» du CEVA, ce projet constitue « une vraie alternative car 36 établissements conchylicoles ont répondu à l'appel à projet. La filière est en crise et la culture des algues est une activité sans contraintes, beaucoup moins exigeante que la culture de l'huître; il n'y a pas par exemple de travail de retournement des paniers à la suite des marées. Il y a moins de contrôle sanitaire et surtout la commercialisation de l'algue est sûre $»^{21}$. Le projet CHACO tend à démontrer la faisabilité de la co-culture algues/bivalves sur des concessions ostréicoles ou conchylicoles. Parallèlement, l'évolution de la réglementation favorable aux doubles cultures algues/bivalve suggère que l'aquaculture multi-trophique intégrée commence à être investie, relayée par des acteurs institutionnels et peut se développer en France de manière synergique et encadrée ${ }^{22}$. Une analyse comparée avec la Chine et des retours d'expérience sur divers territoires littoraux seraient éclairants car les recherches sur la mariculture intégrée ouvrent des potentialités pour des estrans français.

\section{Conclusion}

41 En 2002, la surface de la mariculture intégrée chinoise s'étendait sur près de 1352000 hectares pour une production de plus de 12 millions de tonnes (Chang, Chen, 2008). Malgré le potentiel de la filière, la baisse de la production d'algues à 10 millions de tonnes est la conséquence des nouvelles fragilités des concessions algacoles comme à Dalian ou à Xingang. La diffusion plus grande de pathologies, les capacités de charge des milieux atteintes, les pollutions des écosystèmes conjuguées avec les conflits d'usages sur l'interface terre-mer sont autant de facteurs qui portent préjudice à l'algoculture chinoise (Chang, Chen, 2008). La production marine littorale, pourtant si importante et prometteuse, est elle aussi une victime en fin de chaîne de la très grande pollution des terres et des fleuves continentaux de la Chine mais aussi de l'essor fantastique de son littoral (illustration 5).

L'algoculture chinoise se situe essentiellement sur les côtes de la nouvelle mer mondialisée de la Chine du nord, le golfe de Bohai. Au nord du golfe, le dynamisme de Dalian transforme les côtes de la péninsule du Liaoning car c'est le débouché portuaire 
des provinces peuplées et industrielles du Nord-Est (Liaoning, Heilongjiang et Jilin). Au sud du golfe, l'ouverture actuelle du Shandong sur le monde accélère la littoralisation des hommes et des activités.

Nous pouvons ajouter à cela une contrainte d'ordre financier liée au cours du prix de l'algue. La baisse de la production pour l'année 2010 s'explique par les aléas naturels (nombreux typhons et température des eaux trop douces), par de plus fortes contraintes anthropiques (construction de zone d'industries marines et de logements). Des pratiques spéculatives grèvent la filière chinoise des algues. Lorsqu'elles sont séchées, les algues se conservent très longtemps : il est alors possible de les stocker et d'attendre que leur valeur monte (pour l'année 2010, les algues d'aquaculture et de récolte ont rapporté 7,4 milliards de dollars, FAO 2010). Les algues ont subi une très forte inflation, comme l'ensemble des prix alimentaires en Chine. Leur commercialisation connaît des inconstances nouvelles ${ }^{23}$.

Etudier la culture des algues conduit à l'exploration d'un large éventail de problématiques géographiques, permettant d'étudier les transformations spatiales et agricoles des territoires littoraux et de contribuer à analyser comment nourrir les hommes et gérer les littoraux face à des contraintes territoriales, sociales et naturelles en pleine mutation.

\section{BIBLIOGRAPHIE}

Chang Y., Chen J., 2008. The status of mariculture in nothern China, in Lovatelli A, Phillips M-J, Arthur J-R, Yamamoto K, FAO/NACA Regional workshop on The future of mariculture, a regional approach for responsible development in the Asia-Pacific région, Guangzhou, China, 7-11 march 2006, FAO Fisheries proceedings, Rome, p. 271-284.

Ding L., 2008. Biological assessment of ecologically important areas for the algae taxonomic in the Yellow Sea ecoregion. In Biological Assessment Report of the Yellow Sea Ecoregion, Beijing, Science press, p. 205-218.

Duarte P., Meneses R., Hawkins A.J.S., Zhu M., Fang J., Grant J., 2003. Mathemical modelling to assess the carrying capacity for multi-species culture within coastal waters. Ecological Modelling, $\mathrm{n}^{\circ} 168$, p. 109-143.

Fang J.-G., Sun H.-L., Yan J.-P., Kuang S.-H., Li F., 1996. Polyculture of scallop Chlamys farreri and Kelp Laminairia Japonica in Sungo Bay. Chinese journal of oceanology and limnology, volume $14, \mathrm{n}^{\circ} 4$, p. 322-329.

Fang J.-G., Zhang J.-H., Jiang Zeng J., Mao Y.-Z., 2009. Development of Integrated Multi-trophic Aquaculture in Sanggou Bay, China. Actes du Congrès EAS, novembre 2009 Manille, Publication de la FAO.

FAO, 2010, Annuaire Statistique des pêches et de l'aquaculture 2008. Services des statistiques et de l'information du Département des pêches et de l'aquaculture, Rome, $72 \mathrm{p}$. 
FAO, 2010. The state of world fisheries and aquaculture. Fisheries and Aquaculture Department, Rome, $218 \mathrm{p}$.

Gourlay F., Le Délézir R., Le Fur A., 2011. Atlas de la Bretagne, les dynamiques du développement durable. Paris, Autrement, $104 \mathrm{p}$.

Leclerc V., Floc'h J.-Y., 2010. Les secrets des algues. Versailles, Edition Quae, Versailles, 167 p.

Lucas A. et N., 1980. L'aquaculture dans les mers tempérées. Norois, n 106, p. 237-250.

Neushul P., Wang Z., 2000. Between the Devil and the Deep Sea: C.K Tseng, Mariculture and the Politics of Science in Modern China. Isis, volume 91, $\mathrm{n}^{\circ}$ 1, p. 59-88.

Reviers de B., 2002. Biologie et phylogénie des algues. Paris, Belin, 352 p.

Sanjuan T., 1996. À l'ombre de Hong-Kong. Le delta de la rivière des Perles. Paris, L'Harmattan, 314 p.

Sanjuan T., 2007. Atlas de la Chine. Paris, Autrement, 80 p.

Sanjan T., Trolliet P., 2010. La Chine et le monde chinois, Une géopolitique des territoires. Paris, Armand Colin, $384 \mathrm{p}$.

Tabeaud M., Bodiguel C., 1996. L'algoculture dans le monde et ses contraintes. Annales de géographie, $\mathrm{n}^{\circ}$ 591, p. 480-497.

Troell M., 2008. Integrated mariculture: its role in future aquaculture development. In Lovatelli A., Phillips M.-J., Arthur J.-R., Yamamoto K., FAO/NACA Regional workshop on The future of mariculture, a regional approach for responsible development in the Asia-Pacific région, Guangzhou, China, 7-11 march 2006, FAO Fisheries proceedings, Rome, p. 323-325.

Troell M., Halling C., Neori A., Chopin T., Buschmann A.H., Kautsky N., Yarish C., 2003. Integrated mariculture: asking the right questions. Aquaculture, $\mathrm{n}^{\circ} 226$, p. 69-90.

Tseng C.K., 2004. The past, present and future of phycology in China. Hydrobiologia, $\mathrm{n}^{\circ} 512$, p. 11-20.

Yuz M., Hongsheng Y., Yi Z, Naihao Y., Jianguang F., 2009. Potential of the seaweed Gracilaria lemaneiformis for integrated multi-trophic aquaculture with scallop Chlamys farreri in North China. Journal of applied phycology, DOI 10.1007/s10811-008-9398-1, Springer Science, 7 p.

Zhang J., Rørtveit J., 2004. Aquaculture in China. Beijing, Innovation Norway, 50 p.

\section{NOTES}

1. Lerrat Y., Sassi J-F., 2011. Old chemistry to replace new petrochemistry. Colloque international Alg'n'Chem, Algae, new resources for industry, 7-10 novembre 2011, communication orale, Montpellier.

2. Sanjuan T., 2007. Approcher les dynamiques régionales en Chine. Hérodote, $n^{\circ} 125$, p. 158.

3. Article d'Harold Thibault, «Le silence des autorités chinoises sur la nouvelle marée noire qui touche la mer de Bohai, au nord-est du pays ", in Le Monde, samedi 23 juillet 2011 ; et article d'Harold Thibault, «En Chine, une marée noire très discrète de $840 \mathrm{~km}^{2}$ », in Le Monde, jeudi 7 juillet 2011.

4. Les biologistes marins de l'Institut océanographique de Qingdao et l'Institut d'hydrobiologie de l'Académie des sciences chinoises ont recensé 40000 espèces d'algues marines et 30000 espèces d'algues d'eau douce.

5. FAO, 2010. Annuaire statistique des pêches et de l'aquaculture 2008, p. 57.

6. FAO, 2010. The state of world fisheries and aquaculture, p. 19. 
7. Traitement à partir des chiffres de la $\mathrm{FAO}(\mathrm{FAO}, 2010$, The state of world fisheries and aquaculture, p. 37).

8. Chiffres extraits de l'Annuaire statistique des pêches et de l'aquaculture 2008 de la FAO, 2010, p. 57.

9. L'Institut océanographique de Qingdao dans le Shandong est un organisme national de recherche universitaire chinois pionnier dans l'étude et les techniques de culture des macroalgues.

10. «La culture des algues est vitale pour les populations déshéritées de ces régions. Elle contribue de façon considérable à la paix et à la sécurité ", Article de Joel D. Adriano, «Funding failure gifts seaweed harvest to Philippine rebels ", in Asia Times Online (Bangkok, Hong Kong) du 14 avril 2011, http://www.atimes.com/atimes/Southeast_Asia/MD14Ae01.html, repris dans Courrier international, $\mathrm{n}^{\circ} 1072$, du 19 au 25 mai 2011, p.36.

11. Lerrat Y., Sassi J-F., 2011. Old chemistry to replace new petrochemistry. Colloque international Alg'n'Chem, Algae, new resources for industry, 7-10 novembre 2011, communication orale, Montpellier.

12. voir l'article du Monde daté du 30 novembre 2010 intitulé: «Les algues, symboles de l'inflation galopante en Chine ».

13. Pour une illustration de cette thématique dans un autre espace insulaire, voir les travaux de G. Ramdine portant sur le bassin caribéen : G. Ramdine, «Les terroirs d'aquaculture des algues rouges dans les Petites Antilles, l'exemple de l'île de Sainte-Lucie ", dans Lasserre F. et Lechaume A., Le territoire pensé : géographie des représentations territoriales, Québec, P.U.Q., 2003.

14. Programme des Nations Unies pour le développement (PNUD) - Fonds pour l'environnement mondial - Projet Mer jaune, UNDP/GEF Yellow Sea Project (United Nations Development Programme and Global Environment Facility), WANG Guang-Ce, «Aquaculture of the Seaweedsand Its Usage for Reducing Eutrophication ", Laboratory of Experimental Marine Biology, Institute of Oceanology, Chinese Academy of Sciences, Qingdao,Chine, http:// www.yslme.org/doc/2rmc/CD/Tueday\%20pm/ 20090616\%20Jeju\%20Korea\%20Guangce\%20WANG.pdf

15. repris par le journaliste Lu Minghe du Nanfang Zhoumo - Canton, www.infzm.com; voir aussi «des coquillages à la sauce métaux lourds », article du Courrier international, n 1098 du 17 au 23 novembre 2011, p.19.

16. Rapport sur la qualité de l'environnement marin de la province du Guangdong en 2010.

17. Office national des affaires maritimes, Rapport sur la qualité de l'environnement marin de la mer de Bohai, 2008, State Oceanic Administration, 2008 Report on the Quality of the Marine Environment of the Bohai Sea.

18. Article de Gong Jing, dans le journal Xin Shiji Zhoukan du 14 septembre 2011 «China's Bohai Sea Drowns in Discharged Waste ».

19. Article de Zhu Yishi dans l'hebdomadaire Xin Shiji Zhoukan du 20 septembre 2011 «Crowded Shandong Grabs Sea for Future Growth», http://www.caing.com/, repris dans le Courrier international n¹094 du 20 octobre 2011, « la folie des îles artificielles », p.59.

20. Des scientifiques sud-coréen estiment que 115000 tonnes de nitrogènes sont déversées par la Corée du Sud dans la Mer Jaune pour fertiliser les eaux de cultures [Bashkin V-N, Park S-U, Choi $\mathrm{M}-\mathrm{S}$, Lee C-B, 2002. Nitrogen budgets for the Republic of Korea and the Yellow Sea, Biogeochemistry, volume 57, n¹, (p. 387-403)].

21. Entretien de Sophie Litzler avec Jean-François Sassi en date du 19 avril 2011.

22. "Veiller à ce que le schéma national de développement aquacole intègre l'ensemble des contraintes de gestion intégrée terre/mer, et s'effectue dans une planification stratégique nationale multisectorielle, en considérant les trois filières de production: algoculture, pisciculture et conchyliculture ", in Le Livre Bleu des engagements du Grenelle de la Mer, Actes du Grenelle de la Mer sous la direction de M. Borloo, Juillet 2009, p.36. 
23. Article duMonde daté du 30 novembre 2010 intitulé : «les algues, symboles de l'inflation galopante en Chine ».

\section{RÉSUMÉS}

La production aquacole mondiale a un taux de croissance annuel moyen de 6,2 \% (2003-2008). La production des végétaux marins suit cette tendance avec 15,8 millions de tonnes d'algues cultivées. La Chine est le premier cultivateur mondial avec 10 millions de tonnes mais en 2008 elle a signalé une baisse de $13 \%$ de sa production aquacole. Cet article souhaite montrer en quoi de nouvelles contraintes géographiques peuvent limiter le développement de l'algoculture malgré le grand potentiel de la filière. Nous présenterons un état des lieux mondial de cette activité puis une typologie de ces contraintes. Nous illustrerons cet axe de recherche par des études de cas sur la Chine.

The global aquaculture production has an average annual growth rate of 6.2 per cent (2003-2008). The production of marine plants follows this trend with 15.8 million tons of seaweed farmed. China is the first world farming country with 10 million, tons but in 2008 it reported a 13 per cent drop in its production. Based on this observation, this article intends to show the geographical restrictions that may limit the development of seaweed farming. We shall present an overview of this activity on a global scale then we shall expose a typology of these restrictions. Finally we shall illustrate this research with several case studies.

\section{INDEX}

Mots-clés : algoculture, Chine, environnement, France, littoral

Keywords : China, coastal waters, environment, France, seaweed farming

Thèmes : Sur le Champ - Sur le Terrain

\section{AUTEUR}

\section{SOPHIE LITZLER}

Sophie Litzler, litzler.sophie@gmail.com , est doctorante contractuelle avec mission d'enseignement à l'Université Paris 1 Panthéon-Sorbonne et membre de l'UMR 8586 PRODIG CNRS. Elle a publié récemment :

- Litzler S., 2010. Les algues sont-elles une ressource marine à exploiter pour développer durablement l'espace caribéen? Etudes caribéennes, ressources marines : états des lieux, usages et gestion, numéro en ligne. Paru le 15 avril 2010. URL de référence : http:// etudescaribeennes.revues.org/4389

- Litzler S., 2010. Des usages traditionnels aux nouvelles finalités scientifiques : quels paysages pour les algues? Actes du colloque du CTHS (Comité des Travaux Historiques et Scientifiques), Paysages, avril 2010, à paraître. URL de référence : http://cths.fr/co/communication.php ? id $=4820$ 